\title{
DOENÇA FALCIFORME: PLANO DE CUIDADOS PARA O ATENDIMENTO EM UNIDADES DE SAÚDE DA FAMÍLIA
}

SICKLE-CELL DISEASE: CARE PLAN FOR FAMILY HEALTHCARE UNITS

\author{
Liliany Santana da Silva ${ }^{1}$ \\ Larissa Rolim Borges-Paluch²
}

O objetivo do estudo foi instrumentalizar a equipe atuante nas Unidades de Saúde da Família para realização do acolhimento e atendimento ao paciente com doença falciforme. A pesquisa foi realizada com indivíduos com doença falciforme atendidas nas unidades de saúde da família de dois municípios do recôncavo baiano. A partir dos resultados obtidos produziu-se um plano de cuidados direcionado para esse público contemplando as principais intercorrências/quadro clínico e condutas diante de determinados quadros sintomatológicos. Além disso, retrata os principais problemas identificados e traça estratégias para sua minimização e aprimoramento no acolhimento desse público. O plano possui grande relevância, pois pode subsidiar a tomada de decisão por parte da gestão e contribuir para a melhora do atendimento dos profissionais de saúde envolvidos e no planejamento de ações locais e municipais contribuindo para reduzir as vulnerabilidades e melhorar a qualidade de vida das pessoas com doença falciforme.

Palavras-chave: Anemia Falciforme. Vulnerabilidade em Saúde. Enfermagem em Saúde Comunitária.

The objective of this study was to provide the Family Healthcare Units team with information to improve the support and care of sickle-cell disease patients. The research was carried out with patients of two municipalities of the Recôncavo Baiano, Brazil. The data collected were used to develop a care plan considering the main complications/clinical picture and management of sickle-cell disease patients with different clinical symptoms. Moreover, it describes the main problems observed and devises strategies to reduce them and improve patients' support. The relevance of this research is to inform the management team decision making and to contribute to improve patients' assistance. The plan could also be useful to inform local action planning in order to reduce vulnerabilities and improve the quality of life of sickle-cell disease patients.

Keywords: Sickle Cell Disease. Health Vulnerability. Community Health Nursing.

\footnotetext{
${ }^{1}$ Enfermeira (FAMAM). Mestre pelo Programa de Mestrado Profissional Desenvolvimento Regional e Meio Ambiente da FAMAM, Especialista em Saúde Coletiva com Ênfase em Saúde da Família; Especialista em Docência do Ensino Superior; Docente da FAMAM. http://lattes.cnpq.br/0227762620578905, lilaros2@gmail.com.

${ }^{2}$ Bióloga (UFPR), Mestre e Doutora (UFPR) Docente do Programa de Mestrado Profissional Desenvolvimento Regional e Meio Ambiente da FAMAM, http://lattes.cnpq.br/7311866858164682, larissapaluch@gmail.com.
} 


\section{INTRODUÇÃO}

Os glóbulos vermelhos são células arredondadas e flexíveis, que passam facilmente pelos vasos sanguíneos. Dentro destas células há hemoglobina, que transporta oxigênio dos pulmões aos diversos tecidos do organismo. A maioria das pessoas é geneticamente homozigota (HbAA) (BRASIL, 2012).

Entretanto, alterações genéticas nas hemoglobinas podem acarretar uma anemia hemolítica crônica hereditária. O termo doença falciforme (DF) define as hemoglobinopatias, como a anemia falciforme e a beta talassemia.Todas possuem graus variados de gravidade e manifestações clínicas e hematológicas semelhantes. A alteração mais comum é a anemia falciforme, determinada pela presença da hemoglobina $S$ em homozigose (HbSS) (BRASIL, 2014).

A doença falciforme (DF) é uma das doenças genéticas hereditárias mais comuns no mundo, e os indivíduos com essa patologia podem apresentar diversas sintomatologias e sérias complicações (BRASIL, 2012) (Figura 1).
Entretanto, o indivíduo heterozigoto (HbAS) apresenta o traço falciforme, porém, não é anêmico, não manifesta sintomas e não necessita de tratamento. Entretanto, se essa pessoa desconhece sua condição genética pode haver um aumento da frequência da DF na população geral, pois casais portadores do traço falciforme possuem a probabilidade de $25 \%$, a cada gestação, de gerarem filhos com anemia falciforme (KIKUCHI, 2007).

$\mathrm{A}$ atenção primária à saúde no Brasil tem ênfase na Estratégia de Saúde da Família (ESF), sendo composta por equipe multiprofissional que atua na promoção da saúde e na prevenção de agravos e doenças. A equipe inclui profissionais de nível médio, essenciais para a criação e fortalecimento do vínculo com a pessoa com DF (GOMES et al., 2014).

$A$ atenção às pessoas com DF encontra-se implantada no campo do Sistema Único de Saúde (SUS), nos termos da Portaria $\mathrm{n}^{\circ} 2.048$, de 03 de setembro de 2009 do Ministério da Saúde, embasada pelos artigos 133 e 134. As pessoas com diagnóstico da doença devem ser matriculadas em um programa de atenção integral, vinculado a um hemocentro (AYRES et al., 2008). É imprescindível o

Figura 1. Relação entre fenômenos fisiopatológicos e manifestações clínicas nas doenças falciformes

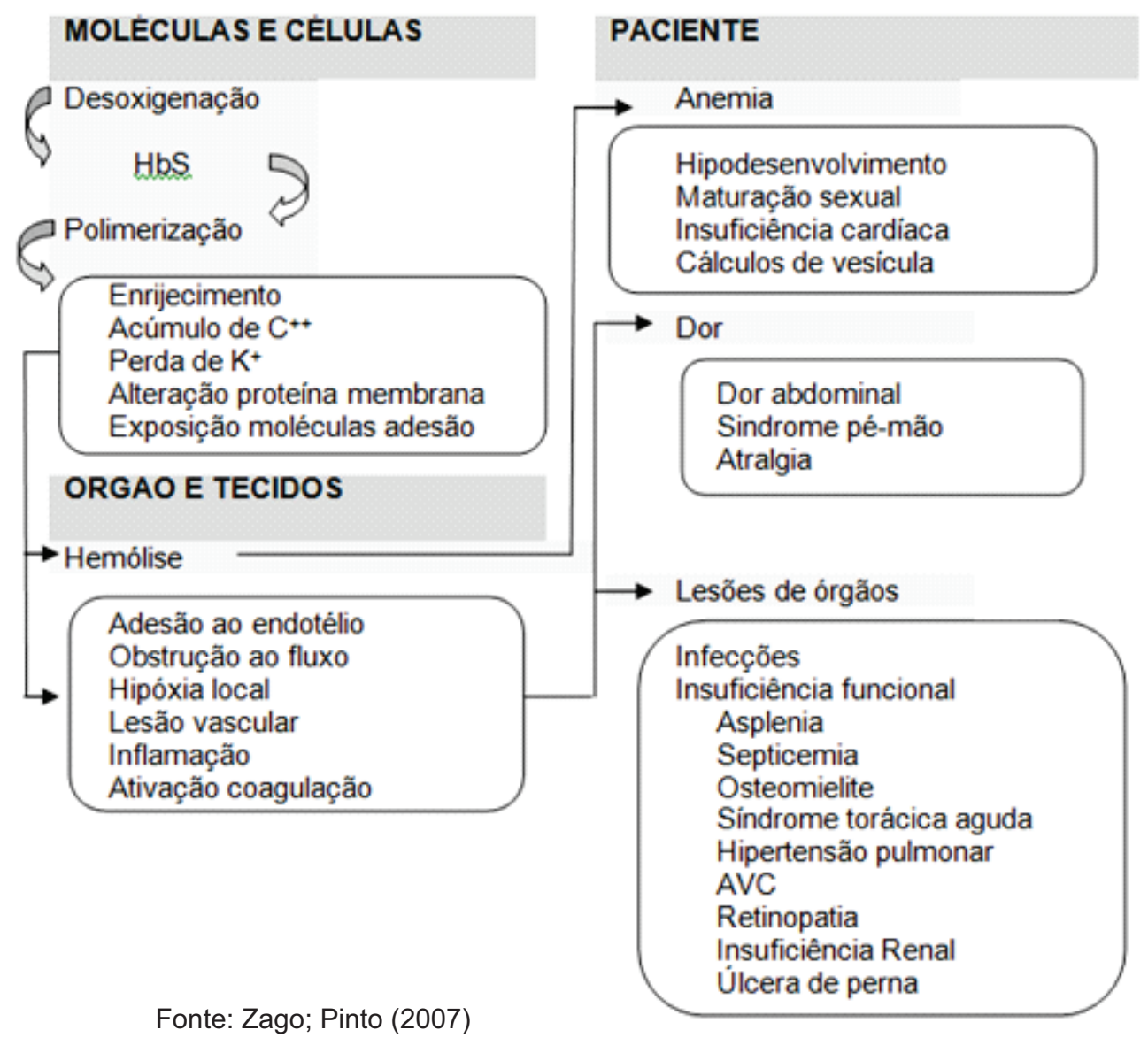


envolvimento dos diversos níveis de atenção no cuidado à pessoa com DF, para que se reduza a morbimortalidade. Assim, as Unidades de Saúde da Família (USF) servem como porta de entrada da rede de atenção à saúde e devem estar organizadas e preparadas para assistir e acompanhar o paciente durante toda a vida (GOMES et al., 2014).

Portanto, a gestão de saúde deve fornecer subsídios para seus trabalhadores para que as equipes agreguem as pessoas com DF aos programas de saúde oferecidos nas ESF, como os de saúde bucal, saúde da criança, saúde da mulher, estratégias de pré-natal de risco, de vigilância nutricional e outros.

Os pacientes com DF devem receber orientações sobre autocuidado, uso de medicações e vacinação (BRASIL, 2014). Além disso, o fortalecimento do vínculo da equipe com o paciente e seus familiares somente é possível por meio do acolhimento e da humanização no atendimento às pessoas com DF, momento importante para o desenvolvimento de ações de prevenção e educação em saúde. Durante o acolhimento os profissionais de saúde devem utilizar todo o conhecimento, visando oferecer orientações que alertem sobre possíveis situações de risco e uma atenção integral para ampliar a capacidade resolutiva para as DF.

O termo vulnerabilidade difundiu-se na década de 1980 no campo da Saúde Pública ao tratar da epidemia da AIDS. A origem essa epidemia foi um fenômeno determinante para que pesquisadores e profissionais de Saúde pudessem repensar o conceito de risco e avançar nas discussões sobre vulnerabilidades, sendo comumente empregado para indicar suscetibilidades das pessoas a problemas e danos de saúde (NICHIATA et al., 2008).

Atualmente, a vulnerabilidade é entendida como algo dinâmico, transdisciplinar e qualitativo que envolve três planos interdependentes: vulnerabilidade individual, vulnerabilidade social e vulnerabilidade programática (AYRES et al., 2003).

A vulnerabilidade individual retrata o nível e a qualidade da informação que os indivíduos dispõem sobre a doença e a capacidade de assimilar essas informações e incorporá-las ao seu cotidiano, ao interesse e às possibilidades efetivas de transformar essas inquietações em métodos de autocuidado e proteção. Portanto, essa vulnerabilidade refere-se à informação que a pessoa dispõe e de como ela utiliza esse conhecimento em benefício próprio (AYRES et al., 2003; PAZ; SANTOS; EIDT, 2006).

A vulnerabilidade social refere-se ao cuidado e acolhimento do indivíduo com DF e está relacionada aos aspectos sociais, políticos e culturais. O plano social está atrelado ao adoecimento e a utilização de indicadores que revelem o perfil da população adscrita, no que tange ao acesso à informação, despesas com serviços sociais e de saúde. Essa dimensão inclui aspectos como grau de escolaridade, disponibilidade de recursos materiais, mobilidade e a identidade social, assim como as características do espaço em que o indivíduo vive, as normas sociais e institucionais, as relações com o outro e as iniquidades (BERTOLOZZI et al., 2009).

Segundo Ferreira et al. (2013), o desenvolvimento de ações preventivas e educativas propostas pelos governantes, assistência à saúde, continuidade e sustentabilidade das ações e políticas públicas são aspectos que descrevem a vulnerabilidade programática. Para Bertolozzi et al. (2009) também deve contemplar o acesso aos serviços de saúde, o planejamento das ações dentro dos serviços, o vínculo que os usuários dos serviços possuem com os profissionais de saúde e as ações.

Diante do exposto, os objetivos do estudo foram identificar as principais vulnerabilidades (social, individual e programática) de indivíduos com doença falciforme; elaborar um plano de cuidados geral e um específico para a população avaliada, visando instrumentalizar a equipe atuante nas USF para realização do acolhimento e acompanhamento de pessoas com doença falciforme.

\section{METODOLOGIA}

A pesquisa foi realizada nas USF de dois municípios do Recôncavo Baiano. Nessas instituições de saúde foi realizada a busca ativa dos indivíduos adultos com doença falciforme. Os critérios de inclusão adotados para os usuários foram: idade superior a 18 anos, diagnóstico confirmado de DF e possuir cadastro na USF de um dos municípios escolhidos para a coleta de dados. O critério de exclusão foi o usuário não aceitar participar do estudo.

Os indivíduos com DF que preencheram os critérios estabelecidos responderam um formulário constituído por questões objetivas e discursivas visando à caracterização e avaliação das vulnerabilidades (social, individual e programática) dessa população.

Em relação à vulnerabilidade social, foram abordadas as variáveis: idade/faixa etária, sexo, estado civil, raça/cor, ocupação, renda, se recebe benefício do estado ou município, nível de 
escolaridade e religião/crença.

Para caracterizar a vulnerabilidade individual abordou-se se o(a) companheiro(a) tem doença falciforme; se possui filhos; se os filhos têm traço ou a doença falciforme; se possui doenças associadas; quais os principais sinais ou sintomas da DF; se possui conhecimento sobre a DF e seu tratamento;

Para determinar a vulnerabilidade programática foram abordadas questões relativas ao acesso aos medicamentos para DF; se recebe vacina para DF na ESF; conhecimento sobre estratégias para se evitar as sequelas e complicações da patologia; conhecimento da secretaria municipal de saúde sobre o seu diagnóstico de DF; se a ESF fornece informação sobre DF; se realiza acompanhamento fora do município e custos com a viagem.

As informações obtidas do formulário sobre vulnerabilidades foram submetidas à análise estatística descritiva.

A pesquisa foi aprovada pelo Comitê de Ética em Pesquisa da Faculdade Maria Milza (CEPFAMAM), parecer 1.024.849.

\section{RESULTADOS}

Após aplicação dos critérios de inclusão/exclusão participaram deste estudo 26 indivíduos adultos.

Em relação à vulnerabilidade social, o perfil da população foi majoritariamente feminino $(69,2 \%)$ e na faixa etária entre 18 e 29 anos (46\%). Em relação ao estado civil, $53,8 \%$ dos pacientes possui companheiro (casado ou união estável). De acordo com as características étnico-raciais ${ }^{3}$ foi verificado que $57,7 \%$ dos indivíduos se autodeclaram pretos e $42,3 \%$ pardos. As demais categorias não foram mencionadas no grupo avaliado.

A ocupação principal da maioria dos entrevistados foi dona de casa $(46 \%)$, e as entrevistadas relataram cuidar da casa e da família e não contribuem com o Instituto Nacional de Seguridade Social (INSS). Outra ocupação frequente foi o de lavrador (15\%).

Quanto à renda familiar, $42,5 \%$ dos entrevistados afirmaram receber menos de um salário mínimo, enquanto $38,4 \%$ recebem um salário. Os indivíduos que recebem mais de um salário possuem cônjuge e/ou recebem auxilio governamental.

Em relação ao recebimento de benefícios do governo, 46\% declararam não receber auxílio, 27\% têm direito ao Programa Bolsa Família, 23\% recebem auxílio doença e 4\% ganham ambos os benefícios.

A população avaliada neste estudo apresenta diversos níveis de escolaridade, sendo que a maioria possui ensino médio completo $(42,4 \%), 27 \%$ ensino fundamental incompleto e 3,8\% afirmaram ter ensino superior incompleto.

Neste estudo, todas as pessoas possuem alguma religião, havendo o predomínio da católica $(69,2 \%)$, seguida pela evangélica $(30,8 \%)$. Outras religiões e/ou crenças não foram mencionadas.

No que tange à vulnerabilidade individual, $69,2 \%$ dos entrevistados declararam que o companheiro não possui o traço ou DF e $30,8 \%$ não possuem conhecimento sobre o companheiro, porque são solteiros ou optaram por não responder a pergunta

Em relação ao número de filhos, $19 \%, 27 \%$ e $12 \%$ possuem 1 , 2 e 3 filhos, respectivamente, e $42 \%$ dos entrevistados relataram que não têm filhos. Nesta pesquisa, $58 \%$ dos filhos herdaram o traço falciforme.

Foi possivel observar que $77 \%$ dos entrevistados sentem algum tipo de dor, sendo as mais citadas: articulações, todo o corpo, membros inferiores, região cervical, lombar, abdome, osso e baço. Em relação ao uso de medicação para amenizar os sintomas, $68,9 \%$ fazem uso de ácido fólico e/ou realizam tratamentos alternativos (como evitar alimentos ricos em ferro).

No que tange à vulnerabilidade programática, $61,5 \%$ dos entrevistados relataram não ter acesso à medicação e $34,6 \%$ a conseguem na USF. Quanto ao acesso às vacinas, $50 \%$ dos entrevistados afirmaram não ter acesso, 7,7\% tomaram a antipneumocócica, $11,5 \%$ contra hepatite A, antipneumocócica, antimeningocócica e antiinfluenza e 15,4\% apenas a anti-influenza. Quando questionados se receberam informação em sua USF $69,20 \%$ afirmaram não receber orientação a fim de se evitar sequelas e complicações da DF.

No que diz respeito ao conhecimento da doença pela Secretaria Municipal de Saúde, 84,6\% dos indivíduos avaliados afirmaram que a secretaria tem ciência do diagnóstico através de relato do agente comunitário de saúde ou porque solicitaram o

\footnotetext{
${ }^{3}$ De acordo com os dados do Instituto Brasileiro de Geografia e Estatística (IBGE) as cinco categorias atualmente utilizadas nas pesquisas de censo demográfico (pela ordem em que figuram no questionário) são branca, preta, amarela, parda e indígena.
} 
transporte para tratamento fora do município de residência.

Quando questionados sobre a realização de acompanhamento da DF fora do município de residência, $69,2 \%$ afirmaram realizar o tratamento em outros municípios. Desses, 34,6\% financiam a viagem com recursos próprios e $34,6 \%$ afirmaram que as despesas são custeadas pela família ou pela Secretaria de Saúde.

\section{Plano de Cuidados da pessoa com Doença Falciforme}

Após consulta a importantes fontes bibliográficas, foi elaborado um plano de cuidados geral e para pessoas com DF e um plano de cuidados específico para a população avaliada com base nas principais vulnerabilidades detectadas.

Dessa maneira, o presente instrumento é uma ferramenta que tem o intuito de auxiliar equipes de USF, pois informa sobre a DF, com ênfase nos principais sintomas e quais cuidados podem ser realizados. Além disso, visa fornecer orientações e/ou estabelecer intervenções, sob a forma de ações/cuidados de enfermagem, baseados em estratégias que atendam às necessidades do indivíduo com DF, da sua família e de toda a comunidade.

O Quadro 1 apresenta um plano de cuidados gerais com as principais intercorrências/quadro clínico e quais as principais condutas diante de diversas manifestações sintomatológicas.

Quadro 1.Plano de cuidado geral

\section{PLANO DE CUIDADO GERAL}

\begin{tabular}{|c|c|}
\hline \hline $\begin{array}{c}\text { INTERCORRÊNCIAS/QUADRO } \\
\text { CLIINICO }\end{array}$ & CONDUTA \\
\hline \hline
\end{tabular}

\section{CRISES ÁLGICAS}

As células em forma de foice têm pouca mobilidade e flexibilidade e podem obstruir o sistema circulatório, impedindo o fluxo de sangue e oxigênio aos tecidos e órgãos (vaso -oclusão). Apresenta m início abrupto e são imprevisíveis podendo ocorrer em qualquer área do corpo.

\section{ANEMIA CRÔNICA}

A destruição precoce dos glóbulos vermelhos causa anemia hemolítica.

\section{INFECÇÕES E FEBRE}

Os doentes falciformes são mais suscetíveis às infecções, como pneumonias, meningite, osteomielite e septicemia.

\section{DACTILITE OU SÍNDROME MÃO E PÉ}

Inflamação aguda dos tecidos que revestem os ossos dos punhos e tornozelos, dedos e artelhos, que ficam edemaciados e não depressíveis ao toque é mais comum em crianças com anemia falciforme.
-Acalmar o paciente.

- Aquecer as articulações.

-Ampliar a oferta de líquidos via oral (3 a 5 litros por dia).

- Prescrever hidratação parenteral.

- Medicar conforme prescrição médica (analgésico e anti

inflamatório).

-Solicitar hemograma com contagem de reticulócitos, raios-X. - Solicitar urinocultura e antibiograma em caso de dor lombar.

- Orientar a família que, em razão de mecanismos compensatórios internos, as pessoas com DF devem se adaptar a conviver com níveis mais baixos de hemoglobina, variando entre 6,5 a $9,0 \mathrm{~g} / \mathrm{dl}$. - Elaborar uma alimentação equilibrada e coerente com o nível social familiar.

saúde com maior resolutividade.

- Encaminhar crianças com temperatura de $39^{\circ} \mathrm{C}$ para um serviço de 


\section{CRISE DE SEQUESTRO ESPLÊNICO}

Retenção de grande volume de sangue no baço (pode estar abaixo dacicatriz umbilical) de forma repentina e abrupta pode estar associada com infecção, comum em crianças.

- Dor no quadrante superior esquerdo, palidez, anemia aguda e baço aumentado.
- Controlar sinais vitais.

- Orientar o familiar a respeito do sequestro esplênico e da importância do controle diário do baço.

- Observar: palidez intensa; letargia; $p$ ele úmida e/ou extremidades frias; sinais vitais pouco perceptíveis echoque hipovolêmico.

- Encaminhar para serviço de urgência.

\section{SEQUESTRO HEPÁTICO}

Dor no quadrante superior direito, anemia aguda e fígado aumentado, mais comum em adultos.
- Controlar os sinais vitais.

- O familiar sobre o sequestro hepático.

- Encaminhar para serviço de urgência.

\section{ICTERÍCIA HEMOLÍTICA}

Devido à destruiçã o rápida dos glóbulos vermelhos por hemólise, há liberação de grande quantidade de bilirrubina, não sendo completamente eliminada pelo fígado e se acumulando no sangue circulante. Se houver grande concentração no sangue, a pele e/ou a esclera ficam ictéricas.

\section{SÍNDROME TORÁCICA AGUDA (STA)}

A STA é definida como um novo infiltrado pulmonar e alguma combinação de febre, dor torácica e sinais e sintomas de doenças pulmonares, como taquipneia, tosse e dispneia.

\section{ACIDENTE VASCULAR CEREBRAL (AVC)}

Interrupção do fluxo sanguíneo no cérebro por infarto cerebral pode ocorrer em crianças. Os sintomas podem ser desde pequenos problemas motores (alteração na marcha) até acometimentos graves (afasia e paralisias completas bilaterais). Frequentemente pode deixar sequelas definitivas, como déficit neurológico e dificuldade de aprendizado.

\section{COMPLICAÇÕES OCULARES}

Em razão dos processos vaso-oclusivos na irrigação dos olhos ou decorrente de processos na parte interna de órgãos, inclusive os sem percepção externa, há formação de cicatrizes, manchas, estrias, comprometendo a saúde ocular com perdas gradativas da visão.

\section{ÚLCERA DE PERNA}

São feridas que surgem ao redor do tornozelo e parte lateral da perna, bastante dolorosas e com tendência a cronificar.
- Informar aos familiares o motivo da icterícia.

- Investigar se há outras causaspara a existência de icterícia. - Orientar sobre a importância da maior ingestão de líquidos. - Em caso de dores abdominais, vômitos, náuseas e/ou febre, a pessoa deve ser encaminhada para serviço médico com maior resolutividade.
- Encaminhar para serviço de urgência para combater hipóxia, cobrir os agentes infecciosos mais frequentes e evitar a sedação excessiva e a hiper-hidratação.
-Doente falciforme que chegar ao serviço de atenção básica com déficit neurológico deve ser encaminhado para serviço médico com maior resolubilidade para a reversão do quadro. - Se apresentar febre deve ser realizado exames para exclusão de meningite.
- Observar a acuidade visual, pois pode ocorrer perda gradativa.

- Observar sinais de hemorragias na esclera.

- Realizar, anualmente, exame oftalmológico para avaliação da função interna dos olhos. 


\section{ÚLCERA DE PERNA}

São feridas que surgem ao redor do tornozelo e parte lateral da perna, bastante dolorosas e com tendência a cronificar.
-As úlceras tendem a se cronificar, requerendo limpeza e troca de curativo , pelo menos, duas vezes ao dia para facilitar a cicatrização.

- Observar sinais de infecção e necessidade de introdução de medicação específica contra infecções.

\section{PRIAPISMO}

É a ereção prolongada e dolorosa do pênis, por obstrução dos vasos que irrigam esse órgão.
- Orientar que o priapismo é uma intercorrênci entre pessoas com DF.

- Reforçar a importância da ingestão diária de líquidos.

- Preservar a privacidade, colocando a pessoa em sala mais reservada e, caso não resolva com hidratação e analgésico, encaminhar para serviço de maior complexidade.

\section{QUELAÇÃO DE FERRO}

Em razão do grau da complicação clínica o, paciente pode necessitar de transfusão de sangue crônica. Em decorrência disso, os níveis de ferro aumentam no organismo, podendo haver acúmulo nas células de órgãos, como fígado, coração e rins.
-Apoiar emocionalmente o paciente e o familiar para garantir a adesão ao tratamento.

- Orientar quanto aos cuidados de enfermagem como manuseio, diluição, conservação do medic amento para evitar contaminação.

- Orientar a respeito dos cuidados com a limpeza da pele do local e da importância dealternância nos locais de aplicação. - Reforçar a importância das avaliações periódicas do hematologista.

- Verificar a utilização da medicação conforme prescrição médica.

\section{CÁLCULO BILIAR}

Dores no quadrante superior direito, náuseas, vômitos podem ser indício de litíase biliar. Pode ocorrer em $14 \%$ das crianças.
- Orientar a respeito da possibilidade de formação de cálculo biliar.

- Orientar sobre a importância de realizar, anualmente, ultrassom abdominal.

Fonte: Kikuchi (2007); Brasil (2014)

Além disso, diversos estudos (BRASIL, 2014; GOMES et al., 2014; KIKUCHI, 2007) afirmam que cabe à equipe de Saúde da Família:

$>$ Realizar educação em saúde, abordar os sinais de alerta, a palpação do baço, o cuidado com grandes variações ambientais (como frio ou calor excessivos);

$>$ planejar, sistematizar e realizar visitas domiciliares;

> verificar medicação, frequência escolar e eventos de dor;

$>$ fornecer ácido fólico;

> realizar curativos, quando necessário;

> priorizar o atendimento, em casos de sinais de alerta;

> garantir imunização (vacinas do calendário básico, antipneumocócica 23 , hepatite $A$, influenza);

$>$ orientar para o autocuidado; realizar avaliação odontológica;

> fisioterapia para redução da dor e preservar a função do membro afetado;

> solicitar exames laboratoriais e de imagem;

> avaliar a necessidade de encaminhar para especialidades (cardiologista, neurologista, oftalmologista, pediatra, ortopedista, entre outros);

> garantir o planejamento familiar;

$>$ orientar quanto ao uso e diluição da hidroxiureia, quando necessário;

> promover a busca ativa das pessoas com doença falciforme;

organizar o atendimento a partir da rede básica;

> ampliar o acesso à assistência integral;

$>$ expandir o conhecimento da situação epidemiológica da doença;

capacitar os recursos humanos; 
$>$ assegurar a resolutibilidade;

$>$ realizar oficinas de trabalho para o planejamento das atividades;

$>$ treinar a equipe de trabalho para o acolhimento e atendimento aos pacientes com DF;

$>$ produzir o conhecimento científico;

$>$ informar à população.

É importante salientar a importância da descentralização dos serviços através das parcerias e pactuações com as coordenações de saúde.

No contexto regional, o acesso e acompanhamento envolve a localização da pessoa, agilidade na obtenção de consultas na USF, atendimento especializado e priorização do atendimento em caso de sinais ou sintomas da doença. A resolutividade tem relação direta com a capacidade dos serviços de saúde em atender às necessidades dos usuários.

O Quadro 2 apresenta um plano de cuidados específico que pode ser utilizado, de maneira genérica, em municípios do Recôncavo Baiano. Ele foi elaborado com base nas principais vulnerabilidades identificadas durante a coleta de dados da presente pesquisa e traça estratégias para minimizá-las visando melhor acolhimento desses usuários.

Quadro 2. Vulnerabilidades e respectivos cuidados para as pessoas com doença falciforme em Unidades de Saúde da Família do Recôncavo da Bahia

\section{VULNERABILIDADES DETECTADAS E CUIDADOS ESPECÍFICOS PARA PESSOAS COM DOENÇA FALCIFORME NO RECONCAVO DA BAHIA}

\section{VULNERABILIDADE SOCIAL}

Falta de recurso financeiro para acompanhamento fora do município de origem

- Garantir transporte para consultas n a Fundação de Hematologia e Hemoterapia do Estado da Bahia (Hemoba) ${ }^{1}$.

- Garantir alimentação nos dias de consulta no Hemoba.

- Planejar o agendamento do transporte para o Hemoba, nas USF durante as consultas de acompanhamento - Ofertar transportes em horários de temperatura amena.

\section{VULNERABILIDADE INDIVIDUAL}

\section{Desconhecimento da população sobre as doenças e o traço falciforme}

- Informar a população sobre a doença falciforme.

-Promover informação genética nas consultas de planejamento familiar, no pré -natal, nas consultas de puericultura e durante a realização de teste do pezinho, realizando salas de espera sobre a temática

\section{Desconhecimento sobre as vacinas}

- Realizar o levantamento de cartões de vacinas.

- Identificar pessoas não vacinadas.

- Realizar a busca ativa das pessoas.

- Esclarecer sobre as vacinas.

- Ofertar as vacinas do calendário básico.

- Solicitar vacinas especiais aos Centros de Referência para Imunobiológicos Especiais (CRIE).

- Realizar aprazamento.

- Esclarecer sobre a importância de retornar para completar o esquema vacinal.

\section{Desconhecimento sobre os sintomas e complicações}

-Esclarecer os principais sintomas da doença e estratégias para evitar as complicações, conforme orientações do Quadro 1. 
Pouca informação sobre o manejo da dor

- Orientar sobre as crises álgicas, fatores e condições que predispõem ao aumento das crises e acolher conforme Quadro 1.

\section{Pouca informação sobre alimentação}

- Orientar a alimentação balanceada, rica em legumes, frutas, feijão, gema de ovo e leite.

- Orientar ingestão de líquidos.

\section{VULNERABILIDADE PROGRAMÁTICA}

\section{Pouco ou nenhum acesso à Estratégia de Saúde da Família (ESF)}

- Identificar os pacientes com traço e doença falciforme.

- Realizar a busca ativa dos pacientes.

- Inserir os pacientes nos programas ofertados na ESF.

- Realizar acompanhamento mensal ou conforme necessidade.

-Entregar cartão de acompanhamento.

\section{Dificuldade no acesso ao ácido fólico}

- Ofertar e garantir o ácido fólico.

- Orientar quanto a sua importância no processo de produção de glóbulos vermelhos.

\section{Dificuldade para agendar consultas com especialidades}

- Ofertar cotas de consultas com especialistas de acordo com levantamento das USF e necessidades dos pacientes (por meio da coordenação da atenção básica e regulação do município).

-Em caso de consultas em outros municípios, agendar e garantir o transporte por meio da coordenação de atenção básica e Secretaria de Transporte

\section{Falta da busca ativa dos pacientes}

- Realizar a busca ativa de pacientes para efetuar consultas, vacinaç ão e acompanhamento, contando com o apoio dos agentes comunitários de saúde

\section{Pouco ou nenhum acolhimento direcionado para esse grupo}

- Realizar acolhimento.

- Garantir consultas.

- Priorizar o atendimento.

- Informar quanto ao retorno.

- Realizar visitas domiciliares.

Fonte: Autoria própria

\section{CONSIDERAÇÕES FINAIS}

A pessoa com DF inspira cuidados e atenção continuada. A equipe de saúde tem a responsabilidade de identificar pacientes com a doença, evitando situações que predisponham à crise e reconhecimento dos sinais e sintomas sugestivos da doença. A equipe deve priorizar o atendimento em caso de febre, dor, aumento súbito da palidez, acentuação da icterícia, distensão abdominal, aumento do baço ou do fígado, tosse ou dificuldade respiratória, priapismo, alterações neurológicas, impossibilidade de ingerir líquidos, desidratação, vômitos e hematúria.

O conhecimento sobre a DF evita perdas de identificação de sinais clínicos de crises e favorece a compreensão dos comportamentos expressos pelos pacientes e das exigências das condutas traçadas por outros profissionais.

É imprescindível que os profissionais que acolhem os pacientes ofereçam também diversas orientações com o propósito de empoderar o paciente e seus familiares sobre os aspectos clínicos e terapêuticos da DF, visando reduzir vulnerabilidades e melhorar a qualidade de vida desses indivíduos. 


\section{REFERÊNCIAS}

AYRES, J.R.C.M., et al. O conceito de vulnerabilidade e as práticas de saúde: novas perspectivas e desafios. Fiocruz. Rio de Janeiro (RJ). 2003. p.117-39.

Disponível em: < scholar.google.com.br/citations?user=Kd6p5gAAAAJ\&hl=em>Acesso em: 14 de set de 2014 .

AYRES, J.R.C.M., et al. Risco, vulnerabilidade e práticas de prevenção e promoção da saúde. In: CAMPOS G.W.S.; MINAYO, M.C.S.; AKERMAN, M.; JÚNIOR, M.D.; CARVALHO, Y.M., (orgs.). Tratado de saúde coletiva. $2^{\text {a }}$ Edição. Rio de Janeiro: Hucitec, FIOCRUZ; p. 375-497. 2008.

BERTOLOZZI, M.R., et al. Os conceitos de vulnerabilidade e adesão na

Saúde Coletiva .Rev Esc Enferm USP. n.2, v.43, p. 132630, 2009.

Disponível em :<www.ee.usp.br/reeusp> Acesso em: 23 de out de 2014.

BRASIL. Ministério da Saúde. Secretaria de Atenção à Saúde. Departamento de Atenção Especializada. Doença falciforme: condutas básicas para tratamento / Ministério da Saúde, Secretaria de Atenção à Saúde, Departamento de Atenção Especializada. Brasília: Ministério da Saúde, 2012. Disponível em: www.bvsms.saude.gov.br. Acesso em: 25 de out. 2015.

BRASIL. Ministério da Saúde. Secretaria de Atenção à Saúde. Departamento de Atenção Hospitalar e de Urgência. Doença falciforme: enfermagem nas urgências e emergências: a arte de cuidar / Ministério da Saúde,
Secretaria de Atenção à Saúde, Departamento de Atenção Hospitalar e de Urgência - Brasília, 2014. Disponível em: www.bvsms.saude.gov.br. Acesso em: 23 de set. 2015.

GOMES, L.X.; TORRES, I.A.P; TORRES, H.C. CADEIRA, A.P.; VIANA, M.B. Acesso e assistência à pessoa com anemia falciforme na Atenção Primária. Acta Paul Enferm, n.27, v.4, p.348-55, 2014 Disponível em: <http:www.//dx.doi.org/10.1590/1982-0194201400058>. . Acesso em: 6 de nov de 2015.

$\mathrm{KIKUCHI}$ B.A. Assistência de enfermagem na doença falciforme nos serviços de atenção básica. Rev. bras. hematol. hemoter. v.29, n.3, p. 331-338, 2007. Disponível e $\mathrm{m}$ www.scielo.br/scielo.php?script=sci_arttext\&pid=\$1516 Acesso em: 28 de set. 2014.

NICHIATA, L. Y. I. A utilização do conceito vulnerabilidade pela enfermagem. Rev Latino Am. Enfermagem., v.16, n.5, p.1-7, 2008. Disponível em: <www.eerp.usp.br/rlae>. Acesso em: 22 de dez 2014.

PAZ, A. A.; SANTOS, B. R. L.; EIDT, O. R. Vulnerabilidade e envelhecimento no contexto da saúde. Acta paul. enferm. [online]. n.3, vol.19, p. 338-342.2006. Disponível e m: ht tp://dx.doi org/10.1590/S0103 21002006000300014 . Acesso em: 05/10/2015.

ZAGO, M.A.; PINTO, A.C.S. Fisiopatologia das doenças falciformes: da mutação genética à insuficiência de múltiplos órgãos. Rev. Bras. Hematol. Hemoter. v.29, n.3, p. $207-214,2007$. Disponível em: $<w w w . s c i e l o . b r / s c i e l o . p h p ?$ script=sci_arttext\&pid=S1516 >.Acesso: 14 de set. 2014. I 